\title{
KIAT BELAJAR SISTEM GERAK KARAKTER ANIMASI
}

\author{
Erika Dignitya Indraswari \\ Jurusan Desain Komunikasi Visual, School of Design, BINUS University \\ Jl. KH. Syahdan 9, Kemanggisan, Jakarta Barat 11480 \\ erika@binus.ac.id
}

\begin{abstract}
Every animator has a different way of planning to make animated characters motion system. Planning makes animation can be done by making the timing including with the drawing motion pose options on the character, making self-video recording contained own acting choices, and studying references in accordance with the animation that will be created. Creating animated characters requires skills in image selection, acting, and timing. Before going through the process of making animation, an animator must know and understand the characters and situations in a scene. Every movement and action should have a reason to show the personality of the characters in order to complete the story supports. In addition to the nature of the characters, an animator also needs to know the situation in a scene. Many animators use animation principles that have been developed by Walt Disney Studios, USA, to improve their animated creations. Yet, many animators also develop their animated creations using principles that have been developed in Japan. However, the discussion in this paper is the animation using the principles developed in the United States.
\end{abstract}

Keywords: animation, character, animator, animation principles

\begin{abstract}
ABSTRAK
Setiap animator mempunyai cara perencanaan yang berbeda untuk membuat sistem gerak karakter animasi. Perencanaan membuat animasi bisa dilakukan dengan cara membuat timing disertakan dengan gambar sketsa pilihan pose gerak pada karakter, membuat rekaman video diri yang terdapat pilihan akting sendiri, dan mempelajari referensi sesuai dengan animasi yang akan dikreasikan. Membuat karakter animasi memerlukan keahlian dalam pemilihan gambar, acting, dan menghitung waktu. Sebelum melalui proses pembuatan animasi, animator harus mengenal dan memahami karakter serta situasi dalam suatu adegan. Setiap pergerakan dan aksi harus mempunyai alasan untuk memperlihatkan kepribadian karakter guna melengkapi dukungan cerita. Selain pembawaan dari karakter tersebut, animator juga harus mengetahui situasi dalam suatu adegan. Banyak animator menggunakan prinsip animasi yang telah dikembangkan oleh Walt Disney Studios, Amerika, untuk menyempurnakan kreasi animasi mereka. Banyak juga animator yang mengembangkan kreasi animasi mereka menggunakan prinsip yang telah dikembangkan di Jepang. Namun, yang dibahas pada tulisan ini adalah animasi yang menggunakan prinsip yang dikembangkan di Amerika.
\end{abstract}

Kata kunci: animasi, karakter, animator, prinsip animasi 


\section{PENDAHULUAN}

Dalam sejarah animasi, film animasi terpopuler pertama adalah film yang diciptakan oleh Emile Cohl di Perancis berjudul "Fantasmagorie" pada tahun 1908. Setelah itu, Winsor McCay di Amerika menyusul membuat film animasi pertamanya berjudul "Litle Nemo" pada tahun 1911 dan dilanjutkan dengan film berjudul "Gertie the Dinosaur" pada tahun 1914. Dengan berkembangnya animasi dan berjalannya waktu, Walt Disney sosok yang menciptakan dan memopulerkan karakter "Mickey Mouse" membuat karya animasi menuju tingkat yang lebih tinggi pada era baru. Dia adalah animator pertama yang menambahkan suara dalam suatu adegan film animasi dengan pemutaran film perdananya berjudul "Steamboat Willie" pada tahun 1928.

Baru saja genap satu abad lamanya animasi tercipta di dunia perfilman. Animasi sudah banyak digemari banyak orang sejak terciptanya animasi gambar tangan atau disebut juga dengan animasi dua dimensi. Bukan berarti animasi dua dimensi terlupakan karena hadirnya animasi tiga dimensi sekarang ini, semua tergantung pada gaya animasi yang ingin dikreasikan. Namun, apapun teknik perencanaan yang digunakan adalah sama.

Menciptakan karya animasi yang sukses diproduksi memerlukan proses pembelajaran yang cukup lama. Karya-karya animasi yang telah keluar di layar kaca biasanya dikerjakan oleh teamwork yang melibatkan banyak pekerja. Dalam produksi animasi membutuhkan seorang modeler, rigger, animator, dan pendukung tim kreatif lainnya. Pada tulisan ini penulis akan membahas lebih spesifik tentang pekerjaan seorang animator dengan tema kiat belajar karakter animasi.

Karakter animasi bisa berbentuk apapun, tidak hanya humanoid saja yang berkaki dua tetapi bisa juga mempunyai kaki yang banyak sepeti binatang atau bisa juga tidak mempunyai kaki sama sekali seperti benda atau tumbuhan. Bentuk apa saja yang akan digerakkan merupakan ciri-ciri dari animasi karakter. Ada berbagai macam cara untuk menciptakan gerakan yang indah dalam pembuatan animasi. Setiap animator mempunyai cara yang berbeda sesuai dengan kemampuannya.

Teknik yang akan dibahas pada karya tulis ini merupakan kumpulan teknik perencanaan animasi dari berbagai sumber yang akurat. Bukan hanya dengan teknik perencanaan animasi saja, tetapi juga dengan prinsip-prinsip animasi yang dikembangkan oleh para animator andal di Disney Animation Studios. Semua teknik dan prinsip animasi jika diterapkan akan membuat karya animasi dengan hasil maksimal.

Tujuan penulisan ini adalah untuk bisa memajukan kreativitas animator Indonesia supaya bisa menyaingi animator-animator yang sukses di luar negeri. Juga, mengingatkan para animator untuk bekerja lebih teliti dalam membuat animasi dan menyadari bahwa begitu pentingnya dasar-dasar prinsip dan teknik animasi yang terkadang sudah terlupakan oleh kebanyakan animator. Animator yang mempunyai dasar dalam prinsip, teknik sampai dengan penyempurnaan animasi yang kuat akan membuat karyanya lebih sempurna di mata para penonton.

\section{METODE PENELITIAN}

Meneliti dari hasil karya karakter animasi yang dibuat oleh mahasiswa pada kelas DKVAnimasi di Universitas Bina Nusantara, terdapat banyaknya kekurangan dalam memahami perencanaan sistem gerak dan mendalami prinsip-prinsip animasi. Kelemahan terlihat dari kurangnya latihan pada gambar dan waktu sehingga tidak terlihat natural. Selain kurangnya dalam sistem gerak dan prinsip juga kurangnya memahami pembawaan karakter yang ingin diceritakan. Membuat animasi 
yang baik memerlukan banyak latihan dan praktik. Mahasiswa hanya harus berlatih lebih rajin di luar jam perkuliahan guna mendalami sistem dan prinsip animasi untuk menjadi animator yang baik.

Animator adalah suatu aktor dengan menggunakan alat seperti pensil, benda, dan komputer. Pertanyaan yang harus ditanyakan kepada animator adalah apakah anda seorang aktor yang baik atau yang buruk. Untuk menjadi seorang animator harus bisa mencoba menceritakan sebuah akting melalui karakter animasi. Bukan hanya dari akting saja, tetapi animasi yang baik harus memiliki kepribadian karakter animasi yang kuat. Akting yang baik adalah akting yang bisa dipercaya dan menarik para penonton.

Selain akting, animator juga harus bisa menggambar dengan tangan sebagai dasar pembuatan animasi yang disebut juga teknik tradisional. Untuk mengerjakan animasi dalam dimensi apapun, animator harus mempunyai keahlian untuk membuat animasi tradisional. Dengan pembelajaran tradisional animasi, seorang animator dapat mengembangkan karyanya dengan animasi tiga dimensi seperti pada animasi stop motion atau CGI (Computer Generated Imagery).

\section{HASIL DAN PEMBAHASAN}

\section{Perencanaan Sistem Gerak Efektif Karakter Animasi}

Langkah awal untuk membuat gerakan pada karakter animasi adalah membuat gambar sketsa yang menjelaskan perencanaan pose, aksi, dan ide tentang apa yang akan karakter lakukan di suatu adegan. Sketsa merupakan gambar cepat yang tidak perlu menggunakan detail dan kelihatan indah. Cara menggunakan teknik ini adalah dengan menggambar setiap karakter melakukan pergantian gerakan pada setiap key pose. Kunci pose, atau yang biasa disebut key pose, adalah istilah yang digunakan untuk menggambarkan posisi-posisi penting atau ekstrim dari sebuah karakter animasi atau benda dalam berekspresi. Metode ini menjiwai karakter dari satu pose ke pose berikutnya dan sangat penting untuk mempermudah pembuatan animasi. Teknik ini membantu memastikan sinkronisasi antara suara dan gambar dimana karakter diberi key pose yang dinginkan oleh animator. Teknik key pose merupakan metode yang paling banyak digunakan dalam animasi 2D dan 3D sampai dengan saat ini.

Selain gambar sketsa, animator mempunyai cara lain untuk merencanakan animasi yaitu dengan mempelajari referensi dari video. Perencanaan ini dibuat oleh animator untuk mendapatkan gerakan tubuh yang lebih spontan. Banyak animator yang merekam diri sendiri dengan cara membuat akting suatu adegan dan banyak juga yang mencari referensi video yang tersedia di Internet. Sudah dibuktikan oleh animator senior dengan cara merekam video diri sendiri akan mempermudah untuk lebih merasakan menjadi karakter animasi yang akan kita buat. Namun, video referensi yang terdapat di Internet terkadang tidak sesuai dengan adegan animasi yang akan dibuat dan pilihan akting tidak seperti keinginan sang animator. Dengan membuat beberapa video pilihan akting yang berbeda, tentunya animator akan memilih akting sesuai dengan kebutuhan cerita. Cara ini akan mempermudah animator untuk memperhatikan setiap detail yang ada dalam video tersebut. Detail dalam pergerakan tubuh yang dinamis, pergantian berat badan dan timing dalam sebuah video akan mempermudah animator untuk memproses animasi.

Banyaknya fakta bahwa animator juga harus pandai berakting karena sangat baik untuk dijadikan bahan referensi mereka. Bahkan, akting itu dilebih-lebihkan untuk menimbulkan kesan exaggeration. Dengan berakting, para animator bisa merasakan bagian sendi mana yang bergerak dan ke arah mana perputaran gerakan itu. Sebagai animator harus mengetahui segala sendi yang bisa digerakkan oleh karakter karena sebagai makhluk hidup ketika menggerakkan salah satu sendi 
utamanya akan berpengaruh kepada sendi yang lainnya. Sesuai dengan yang dikatakan oleh John lasseter: "Animators should focus on the acting...make the characters think and act...start with the body first, next focus on the eyes, and last focus on the mouth. When reviewing reels we look at the acting first."

Aksi dalam karakter animasi mengomunikasikan suasana, sikap, kreasi atau ide terhadap karakter yang berkaitan dengan cerita. Untuk mempermudah animator mendapatkan jiwa karakter yang akan dianimasikan, animator harus mengenali sifat karakter dan mengetahui situasi dalam suatu adegan. Setelah animator melakukan perencanaan pembuatan animasi dan mempunyai banyak pilihan ide yang menarik, pastinya animator akan mudah untuk melakukan langkah berikutnya.

\section{Prinsip Dasar Animasi}

Prinsip dasar animasi telah dikembangkan oleh Walt Disney Studios pada tahun 1930-an. Dalam animasi banyak momentum yang mengagumkan dibuat tanpa referensi, pengetahuan, dan prinsip dasar animasi. Dengan menggunakan prinsip dasar animasi ini, gerakan animasi akan lebih hidup dan menarik. Berikut adalah penjelasan singkat tentang 12 prinsip animasi.

Perapatan dan peregangan (squash and stretch) akan memberikan ilusi pada berat dan isi suatu pergerakan karakter. Kegunaan prinsip ini tergantung kepada apa yang diperlukan pada adegan animasi tersebut. Misalnya animasi pada bola karet, pada saat bola membentur permukaan dan memantul akan terlihat ilusi seolah-olah perapatan isi volume sehingga membentuk oval seperti bola tergencet sedangkan sebaliknya pada saat bola itu melaju ke udara akan terlihat oval lonjong keatas seperti adanya peregangan dalam isi volume pada bola tersebut. Berbeda halnya dengan menganimasikan bola plastik, pada saat bola plastik memantul pada permukaan dan melambung ke udara tidak akan terjadi prinsip ini karena sifat permukaan bola plastik ini lebih keras dari pada bola karet. Perhatikan gambar 1.

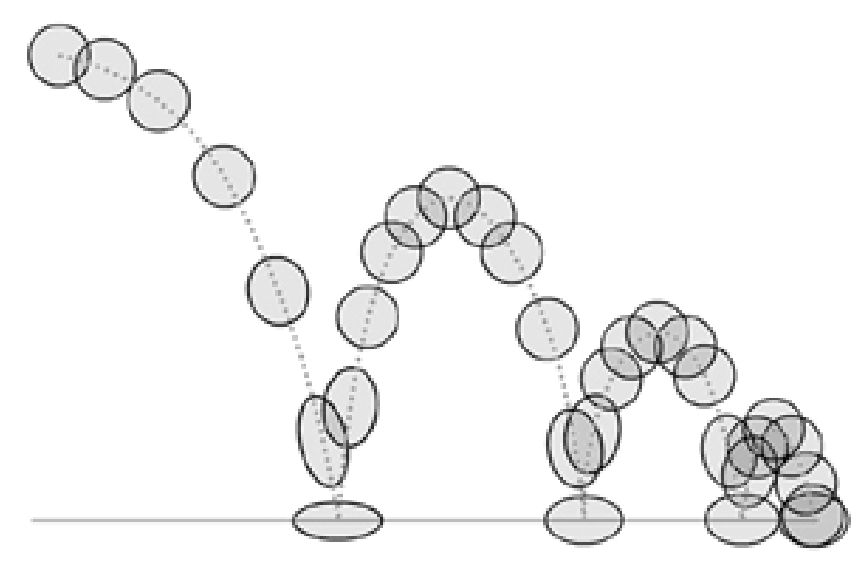

Gambar 1 Contoh perapatan dan peregangan pada animasi bola memantul

Antisipasi merupakan gerakan bertolak belakang dengan gerakan selanjutnya yang dilakukan sebelum beraksi. Hampir setiap gerakan yang bernyawa dalam kehidupan nyata mempunyai antisipasi di setiap ingin melakukan sesuatu karena sebagai mahkluk hidup kita mempunyai yang dinamakan 
refleks. Seperti tangan manusia yang hendak ingin memanah seperti gambar diatas, tangan kita akan menarik benda yang akan ditarik oleh karet kearah belakang adalah gerakan antisipasi sebelum penembakan, antisipasi ini sangat menentukan kecepatan pada tembakan, jika antisipasi tarikan panah lebih ditarik kebelakang maka panah akan menembak lebih kencang dari pada hanya ditarik sedikit. Lihat gambar 2.

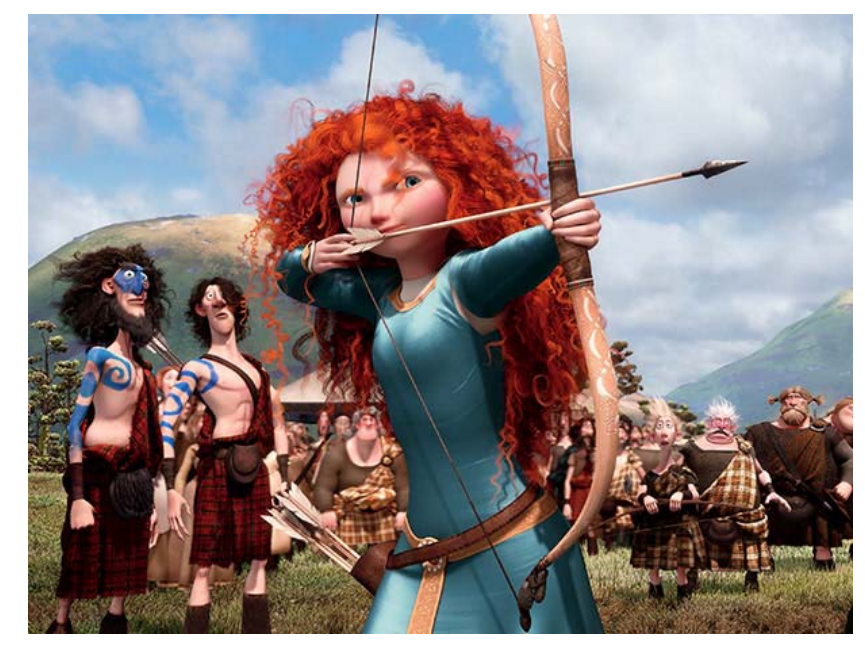

Gambar 2 Contoh gerakan antisipasi dalam film Brave 2012

Tampilan pertunjukan (staging) dari posisi sudut kamera bisa membantu animator untuk menyampaikan ide dan cerita kepada penonton. Sudut kamera yang efektif digunakan biasanya adalah long, medium, atau close-up shots. Contohnya pada adegan misterius, sering digunakan long atau medium shot. Sedangkan untuk melihat ekspresi secara fokus pada karakter, digunakan close up shot. Background dan animasi harus bekerja sama untuk membuat tampilan pertunjukan maksimal.

Straight ahead \& pose to pose adalah suatu teknik pengerjaan animasi yang dilakukan dengan cara menggambar satu per satu, dari awal sampai akhir cerita. Hal ini dimaksudkan untuk memperlihatkan konsistensi pada gambar animasi tersebut, dan dengan cara menggambar kunci pergerakan animasi (keyframe) saja. Sedangkan di antaranya (in-between), dikerjakan oleh asisten animator. Pengerjaan pose to pose banyak digunakan di industri animasi.

Gerakan mengikuti dan aksi tumpang tindih (follow through \& overlapping action) merupakan gerakan pelengkap dalam animasi. Follow through adalah bagian karakter seperti rambut atau ekor yang masih bergerak ketika karakter baru saja berhenti bergerak. Overlapping action adalah gerakan reaksi dari anggota tubuh karakter seperti gerakan sederhana pada saat berjalan lengan mengayun ke arah depan sedangkan pergelangan tangan melakukan gerakan ke arah sebaliknya.

Percepatan dan perlambatan (slow in and slow out) adalah gerakan seperti melempar dan memantulkan bola. Pada bola yang dipantulkan akan terjadi percepatan di mana tidak terdapat gambar yang banyak sedangkan bola yang dilambungkan keatas akan melambat di udara sehingga mempunyai lebih banyak gambar pada animasinya.

Gerakan garis lengkung ( $\operatorname{arcs}$ ) dalam animasi akan terlihat lebih alami. Hampir semua gerakan animasi membentuk sebuah garis lengkung kecuali gerakan alat mekanis seperti robot. Gerakangerakan yang tidak memiliki garis lengkung biasanya akan terlihat seperti gerakan patah-patah dan tidak natural. Untuk lebih jelasnya, perhatikan gambar 3 berikut. 


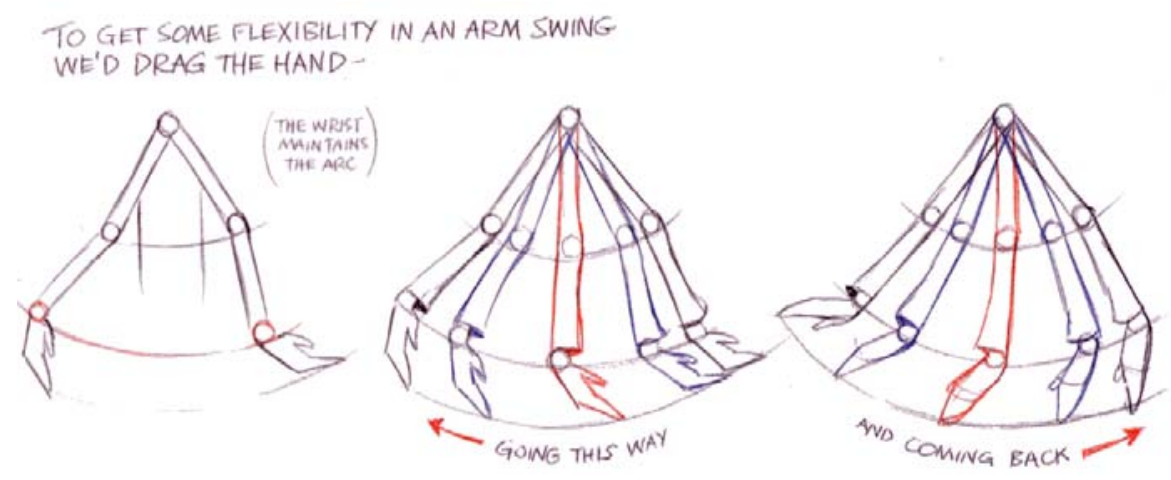

Gambar 3 Contoh gerakan garis lengkung pada animasi tangan Sumber: Animation Survival Kit by Richard Williams

Aksi sekunder merupakan tindakan sampingan untuk memperkaya tindakan utama dan menambah dimensi lebih banyak pada karakter animasi. Semua tindakan pada aksi setiap karakter harus saling bekerja sama. Seperti orang yang kebingungan bukan saja diperlihatkan dari ekspresinya saja, tetapi bisa ditambahkan aksi supaya lebih menarik seperti menggaruk kepala, atau dengan jari menyentuh dagu sehingga memperlihatkan karakter tesebut sedang kebingungan dan berpikir.

Keahlian dalam waktu (timing) dengan metode menyempurnakan teknik. Berbagai percepatan dan perlambatan waktu sesuai dengan referensi dan perasaan akan memperlihatkan suasana dalam adegan dan ekspresi karakter pada animasi.

Gerakan melebih-lebihkan (exaggeration) biasanya terdapat pada animasi cartoony. Wajah, ekspresi, pose, sikap dan tindakan seperti yang ada di referensi dibuat gerakan yang lebih ekstrem. Gerakan yang tidak akurat ini bisa menarik perhatian para penonton agar lebih menarik.

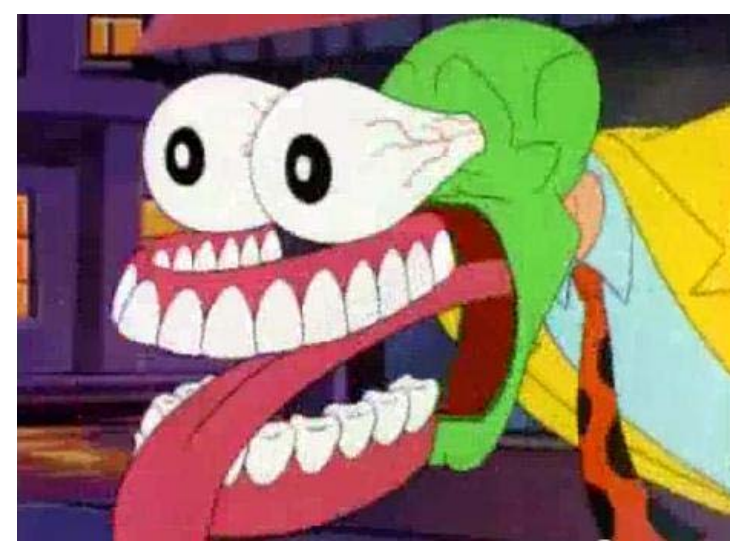

Gambar 4 Contoh gerakan melebih-lebihkan dalam film The Mask

Prinsip menggambar dengan solid berupa bentuk, volume, dan ilusi tiga dimensi berlaku untuk animasi seperti dalam sistem menggambar akademis. Cara dan gaya menggambar kartun klasik pada awalnya menggunakan sketsa pensil, yang dikembangkan menjadi berwarna, gerakan karakter ilusi tiga dimensi yang pempunyai ruang dan gerakan empat dimensi yang mempunyai gerakan waktu. 
Karakter animasi harus mempunyai daya tarik (appeal). Daya tarik bukan hanya sekadar lucu dan menggemaskan. Semua karakter mempunyai daya tarik kepribadian sendiri seperti pintar, cerdik, jahat, serius, bandel dan lain-lain.

\section{Penyempurnaan dalam Animasi}

Hal yang paling penting adalah mengomunikasikan pose aksi pada karakter. Pemilihan pose harus berdasarkan apa yang ingin disampaikan animator kepada penonton. Pose tubuh disesuaikan dengan ekspresi muka sehingga lebih mudah bagi penonton untuk mengerti jalan cerita dalam animasi tersebut. Memang tidak ada peraturan untuk menyimpan emosi karakter, tetapi sebaiknya karakter bisa menonjolkan emosi, niat, dan meningkatkan daya tarik. Lihat gambar 5 berikut untuk contoh key pose.

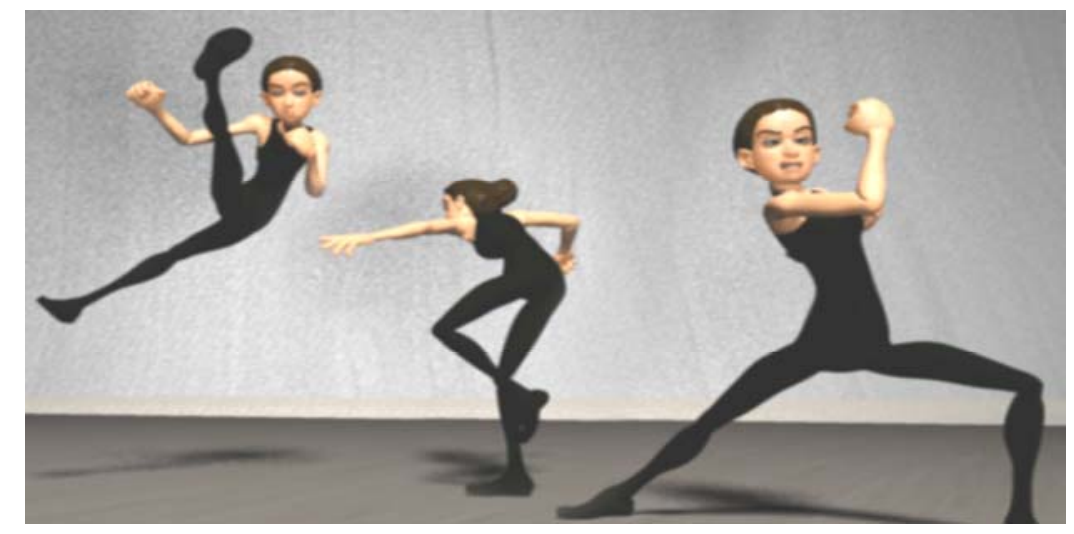

Gambar 5 Contoh key pose gerakan tubuh Sumber: Karya Pribadi

Dalam memilih key pose harus memilki garis aksi yang kuat. Garis Aksi dalam karakter adalah salah satu aspek yang paling penting dari berpose. Seperti contoh di atas, menggambarkan tindakan fisik penting yang emosional dalam suatu adegan. Jika salah satu key pose terhapus, gerakan akan menjadi cacat atau tidak sempurna. Penentuan gerakan key pose dengan garis aksi yang tidak kuat juga akan membuat animasi kurang sempurna. Untuk itu, animator harus sangat berhati-hati dalam menentukan gerakan key pose ini untuk menyempurnakan sebuah adegan animasi.

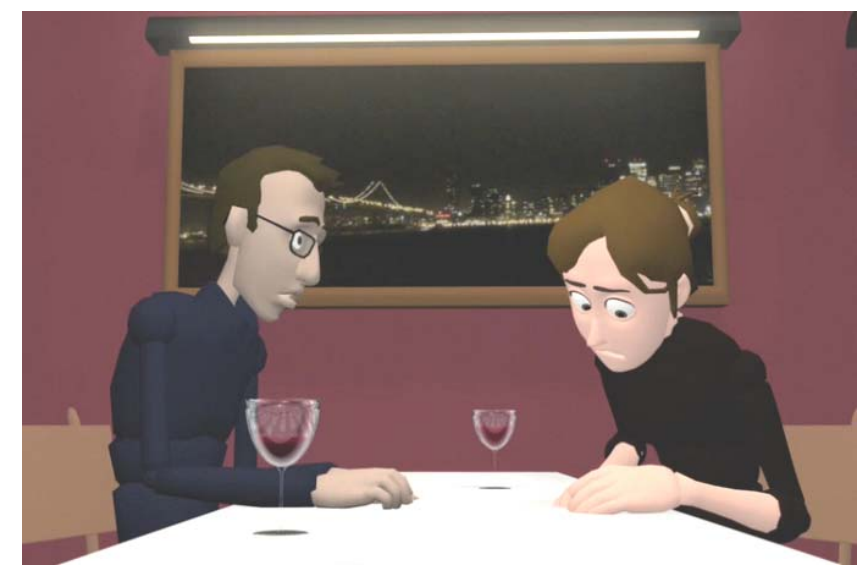

Gambar 6 Karakter perempuan tidak menatap mata lawan bicara Sumber: Karya Pribadi 


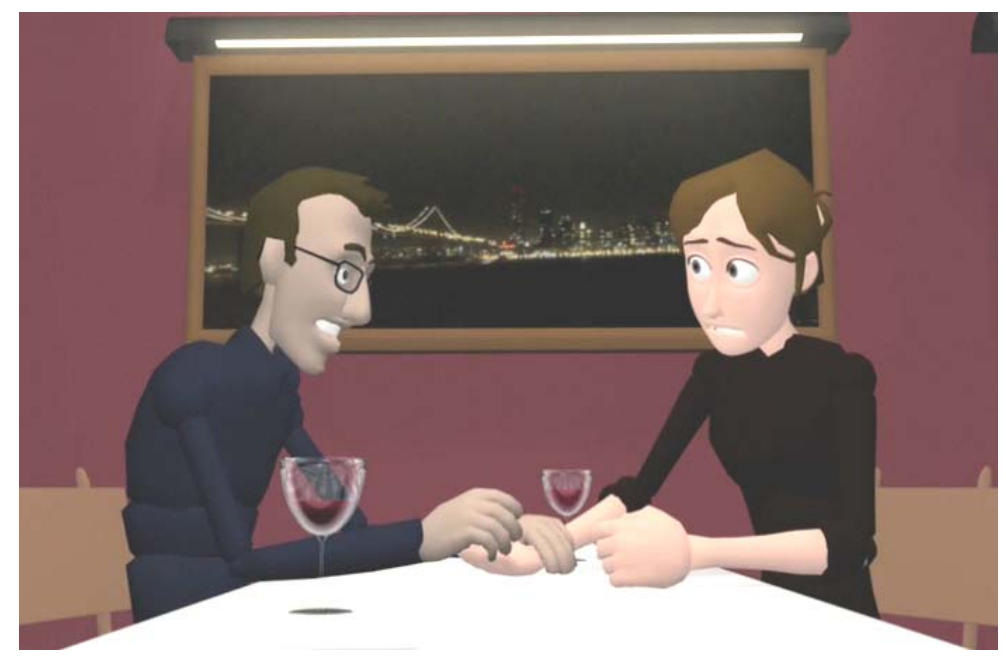

Gambar 7 Karakter perempuan menatap mata lawan bicara Sumber: Karya Pribadi

Pandangan mata pada karakter merupakan hal yang penting dalam suatu adegan. Sebagai animator harus mengetahui ke arah manakah karakter akan melihat, apa yang sedang dilihat. Sebagai contoh, ada dua karakter yang sedang melakukan percakapan. Jika karakter itu merasa tidak nyaman, sedang berpikir, tegang, malu atau berbohong, karakter tersebut tidak akan melihat lawan mainnya dengan tatapan mata. Begitu juga sebaliknya jika kedua karakter sedang melakukan percakapan yang serius atau melakukan aksi terkejut, mereka akan saling melihat satu sama lain.

Perhatikan gambar 6 dan 7 di atas. Arah pandangan mata sangat membantu animator untuk memperlihatkan kepada penonton apa yang ingin disampaikan dalam cerita. Pandangan mata juga bertujuan untuk mempermudah penonton mengerti situasi apa yang terjadi didalam adegan tersebut. Jika karakter animasi tidak mempunyai mata, bisa digantikan dengan gerakan kepala untuk memperlihatkan ekspresi.

Bagi seorang animator untuk membuat karakter lebih hidup itu merupakan nilai tambah. Dengan memberikan detail gerak pada animasi akan membuat animasi lebih terlihat realistis. Seperti dari gerakan kedipan mata atau dari ekor binatang akan sangat memengaruhi karakter untuk terlihat hidup. Kedipan mata mempunyai alasan tersendiri mengapa karakter tersebut mengedipkan kedua matanya. Atau, mengapa karakter hanya berkedip sebelah mata.

Hal yang terakhir dikerjakan oleh animator adalah memoles animasi menjadi lebih halus atau disebut juga dengan polishing/polish. Pada saat animator sudah menentukan semua gerakan yang ada dalam suatu adegan, animator bisa menambahkan sentuhan polish untuk penyempurnaan animasi. Tentunya animator sudah mempunyai keyakinan bahwa tidak akan membuat gerakan perubahan besar pada animasi tersebut sebelum melakukan polish. Tujuan polising pada CGI adalah untuk membersihkan titik-titik yang berada pada setiap kontroler yang mempunyai gerakan pada editor grafik (kolom grafik pada suatu perangkat lunak animasi). Polishing juga dilakukan untuk menyempurnakan animasi tradisioal dengan cara menambah atau mengedit gambar supaya terlihat lebih halus. Proses ini membutuhkan waktu cukup lama karena harus sangat teliti dalam pengerjaannya. 


\section{SIMPULAN}

Pembahasan langkah-langkah pembuatan animasi ini ditujukan untuk seniman animasi Indonesia untuk lebih berkarya lagi. Pembahasan karya tulisan ini merupakan hasil dari buku tentang ilmu dasar animasi yang diterbikan oleh para animator handal yang telah memproduksi banyak film layar lebar. Selain itu, banyak juga inspirasi dari pengalaman pribadi saya sebagai animator Indonesia.

Sangatlah penting bagi animator untuk membuat penonton mengerti bagaimana situasi dalam sebuah cerita dari gerakan tubuh karakter. Dengan cara menarik perhatian penonton, hindari gerakan animasi yang tidak mendukung jalannya cerita dan hanya akan membuat penonton bingung dan bosan. Pengamatan pengalaman hidup juga bisa menjadi sebuah ide dan inspirasi seorang animator. Dalam hidup banyak kejadian menarik yang terkadang sangat mengejutkan dan membuat kita ingat akan sesuatu. Segala hal yang menarik akan lebih mudah diamati dan bisa digunakan untuk mendukung kreasi animasi sang animator.

Bisa disimpulkan bahwa animator dan aktor sama-sama memiliki pekerjaan yang serupa yaitu harus mengekspresikan gerakan mekanik tubuh, wajah, dan presentasi artistik. Sebagai animator sebaiknya harus pintar beraksi seperti aktor untuk menjadi bentuk referensi sendiri karena tidak semua peristiwa yang ingin diperlihatkan dalam suatu adegan animasi bisa diambil dari video referensi yang beredar di Internet/media lainnya. Pekerjaan animator bahkan mempunyai bobot yang cenderung berat karena bukan sulit pembelajarannya tetapi membuat animasi membutuhkan keterampilan untuk menghibur penontonnya.

\section{DAFTAR PUSTAKA}

Goldberg, E. (2008). Character Animation Crash Course!. Los Angeles: Silman-James Press.

Hooks, E. (2003). Acting for animators. London: Heinemann.

Whitaker, H., Halas, J. (2005). Timing for Animation. Massachusetts: Focal Press.

Williams, R. (2001). Animation Survival Kit. New York: Faber and Faber. 